\title{
Poverty, Inequality, and Disasters - An Introduction to the Special Issue
}

\author{
Jasmin Groeschl ${ }^{1} \cdot$ Ilan Noy $^{2}$ \\ Published online: 22 April 2020 \\ (C) Springer Nature Switzerland AG 2020
}

In recent years, the economic consequences of disasters and global climate change have received increasing attention, most recently thanks to the activism of young people around the world. The increased impacts of disasters and climate change have significant effects on human and economic development, particularly on the distribution of income and wealth, and on poverty. These impacts raise serious economic, political and social concerns, which have generated a new interest in research both on the factors that contribute to increased poverty and inequality, in this context of disasters and extreme weather, and on the policies designed to reduce them.

This special issue, "Poverty, Inequality, and Disasters," consists mostly of papers presented in the CESifo Venice Summer Institute Workshop on Poverty, Inequality and their Associations with Disasters and Climate Change, held in June 2019 on the island of San Servolo in the Bay of Venice, Italy. The empirical analysis of how extreme natural hazard events impact the poor, and affect the distribution of economic outcomes was the main theme of the workshop.

Based on much previous work they have undertaken for the World Bank, Hallegatte and coauthors review the literature on poverty and disasters and describe the plethora of evidence that it is the poor that are disproportionally affected by disasters. They further describe the roles of exposure, vulnerability and socio-economic resilience as factors explaining the vicious circle they identify, whereby disasters increase poverty, and the poor are more vulnerable to disasters. In their telling, public policy should therefore consider poverty reduction as a credible disaster risk management strategy, and vice versa.

Aldrich and Tan explore the water resilience of Mexican households after a major earthquake in "Oasis of resilience?". Their empirical investigation of rain water harvesting systems takes place in a high poverty peripheral community in Mexico City. In exploring the drivers of demand, adoption and speed of diffusion of a policy intervention for increased rain water harvesting, they find that vulnerability plays a major role.

Ilan Noy

ilan.noy@vuw.ac.nz

1 ifo Institute, Ludwig-Maximilians-Universität München \& CESifo, Poschingerstrasse 5, 81679 Munich, Germany

2 School of Economics and Finance, Victoria University of Wellington, Wellington, New Zealand 
Exploring the impact of multiple weather shocks on household welfare in Mozambique, Baez, Caruso, and Niu find high vulnerability in consumption, human capital accumulation and poverty rates for various extreme weather risks. They also explore the risk-coping strategies that households employ and the price mechanisms that impact the food markets they rely on. Across the African continent, on its West Coast, Erman and coathors investigate exposure, vulnerability and socio-economic resilience to a flood in Accra, Ghana. They also show that poor households are the most severely affected. In their sample, a third of households have not recovered even 2 years after the flood. They suggest that policies should see flood management as a component of poverty reduction and should particularly target lowresilience households with little access to coping and recovery mechanisms.

Two papers investigate the impact of disasters on inequality. De Alwis examines how household income and consumption in Sri Lanka recovered after the catastrophic Indian Ocean tsunami of Boxing Day 2004 (an event that killed about 35,000 people in Sri Lanka). Interestingly, she finds no evidence for increased inequality associated with the long-lasting recovery from this catastrophic shock. This, she argues, is most likely related to the large volume of assistance received because of the global media attention that followed this event. Sedova, Kalkuhl and Mendelsohn, in contrast, investigate the distributional implications of weather fluctuations on inequality in rural India. They find that poor farming households respond more adversely to extreme weather, which aggravates rural inequality. They point out that, without assistance, this increased inequality may only get worse as the frequency of extreme events is predicted to increase in India as a consequence of anthropogenic climatic change.

Le, in another contribution, explores the impact of floods on household welfare in SouthEast Asia, but does not focus particularly on inequality. She finds that flooding reduces agricultural household income but generates extra non-agricultural income. Still, her data shows that the subjective well-being of households affected by floods is lower. Similar to De Alwis, she identifies that remittances received by affected households are an effective coping strategy for rural households.

Using typhoon remote sensing data from the Phillipines and looking at household consumption expenditure and ex ante vulnerability to poverty, Skoufias and co-authors investigate the impact of typhoons on the probability of falling into poverty. In line with many of the other papers in this special issue, they find that experiencing a typhoon (a tropical cyclone) increases the likelihood of a household to fall below the poverty line.

Finally, Sohnsen looks at several drought indicators that are used in the scientific literature and investigates their suitability to understand the socio-economic implications of slow-onset droughts. He shows that findings on the impact of droughts in Ethiopia are partially dependent on the drought indicator used. This paper thus raises methodological questions about the right metric that should be used to measure drought conditions. It also points out the difficulty in designing policy that is dependent on this array of different findings on the impact of droughts on the consumption of rural households.

Overall, the papers of this special issue contribute to a detailed understanding of household vulnerability and resilience across various types of natural disaster (tropical cyclones, floods, droughts, tsunamis, etc.) and a variety of locations (Mexico, Mozambique, Ghana, Ethiopia, the Philippines, India, Thailand, Vietnam and Sri Lanka). They provide new insights on the implications on household welfare and consumption patterns, and on the impact of natural disaster shocks on inequality and poverty, as well as policy implications arising from this work. As described by Hallegatte et al., the final goal of these policies should be the effective 
reduction of exposure, vulnerability and an increase in socio-economic resilience, which are clearly related to less inequality and lower poverty, but may provide additional co-benefits to the larger economy.

When we initially posted a call for papers for the workshop, we received a record number of submissions (140 submissions). Clearly, the topic is viewed as important, and one in which the economics research community rightly feels it can contribute to. Disappointingly, however, all of these papers focused on disasters and extreme weather events, and none had a specific focus on climate change. We find this surprising and puzzling. Still this absence provides us a strong signal that there is an important opportunity for our profession to focus on a topic that has not yet received enough professional attention - and one which can generate significant difference in the lives of disadvantaged people all over the world and for years to come. We hope that our readers will take this opportunity, and start shining a brigher light on this nexus of poverty, inequality and climate change. Finally, and most importantly, we would like to express our gratitude to the authors, the workshop discussants, and the reviewers of the journal for their effort in contributing to this special issue.

Publisher's Note Springer Nature remains neutral with regard to jurisdictional claims in published maps and institutional affiliations. 